\title{
Predictors and Characteristics Associated with use of Complementary Health Approaches among Cancer Patients
}

\author{
Hala Ibrahim Abo Deif,*Amel Saied Mahmoud \\ Lecturers of Medical-Surgical Nursing, Faculty of Nursing, \\ Cairo University, Egypt. \\ *Email of the corresponding author: amalsaied19@yahoo.com
}

\begin{abstract}
Complementary health approach use is growing over the past 15 years among cancer patients, either in Western countries or in the Far East or in developing countries. So it has undoubtedly gained medical, economic and research importance. Aim: to assess use, predictors and characteristics associated with use of complementary health approaches among patients with cancer. Research design: a descriptive exploratory research design will be utilized. Setting: the study was conducted in the Oncology and Nuclear medicine department affiliated to one of the University Hospital, Cairo-Egypt. Subjects: a convenient sample of 150 adult male and female cancer patients who fulfill the inclusion and exclusion criteria enrolled in the study. Tool: a 21-items questionnaire covering patient demographics features (6items), treatment-related variables (4items), characteristics and predictors of complementary health approach (11items) was used. Results: $(67.3 \%)$ of the study sample used complementary health approaches in association with the conventional treatment of cancer, the most frequent used types of complementary health approach were herbal products, massage, and meditation. Characteristics of complementary health approach users were young age, male patients, those with decreased activity of daily living and patients with genitourinary and blood cancer; predictors of complementary health approach use were young age (18-30) (OR4.9 and $\mathrm{p}=0.010)$, decreased activity of daily living (OR .346 and $\mathrm{p}=0.033$ ).Conclusion: patients living with cancer may be actively using a variety of complementary health approaches while also undergoing conventional cancer treatments.
\end{abstract}

Keywords: predictors, characteristics, use, complementary health approaches, cancer patients.

DOI: $10.7176 / \mathrm{JHMN} / 58-12$

\section{Introduction}

Cancer patients have been turning to complementary health approaches (CHA) in ever increasing numbers over recent decades. Cancer is one of three leading causes of death in developing countries; associated with significant disabilities and is considered as a major public health problem. According to World Health Organization (WHO), it is expected that cancer rates will be doubled by 2030 (Abdelmoaty et al., 2018).

Cancer patients and their families face the trauma of distress, worries and immense fear; they seek all possible options of effective treatment. Some patients also search for the CHA option. Complementary health approach is of critical importance to cancer patients. From an oncologist's point of view, methods different from conventional treatments are critical as well, at least because of constant requests by patients and safety issues due to unknown interactions with classic anticancer therapeutics (Fremd et al., 2017).

Complementary health approach (formerly referred to as complementary and alternative medicine) has been described as "diagnosis, treatment and/or prevention which complements mainstream medicine by contributing to a common whole, satisfying a demand not met by orthodoxy, or diversifying the conceptual frameworks of medicine", several factors are believed to contribute to the popularity of CHA; these can be broadly classified as "push" and "pull" factors. Among the pull factors (i.e. features that attract people to CHA are holistic healthcare beliefs, preference for active healthcare participation, positive past experience with a CHA practitioner, desire for an egalitarian healthcare provider and perceived safety and effectiveness of CHA(Deng \& Latte-Naor, 2018).

Hall et al., (2018) define CHA as 'a diverse group of healthcare practices not generally considered part of the conventional medical curriculum, in addition literature review explored modalities including (but not limited to) acupuncture, aromatherapy, Chinese medicine, chiropractic, homeopathy and naturopathy.

Awareness of and interest in complementary therapies is increasing among patients with cancer hence the National Center for Complementary Medicine (NCCM) characterizes five major types of these nontraditional therapies: whole medical systems (eg, naturopathy, traditional Chinese medicine); mind-body medicine (eg, meditation, prayer); biologically based practices (eg, vitamins, herbal products, nutritional supplements); 
manipulative and body-based practices (eg, massage, chiropractic); and energy medicine(Letourneau, 2018).

Considerable number of people is turning to complementary health approach. In the context of CHA use it has been suggested that people who use CHA either suffer from chronic conditions that might not have been treated satisfactorily by conventional medicine or have life-threatening diseases and use CHA because they are experiencing psychological distress and will try anything that might offer a cure ,in addition the motive for CHA use could be to reduce the side-effects of chemotherapy(Bishop \& Lewith, 2010).Also; previous studies suggest that patient characteristics that are predictive of CHA cancer are generally younger and have higher socio-economic status, being female, being more highly educated and having poorer health status than nonusers(Pedersen, Christensen, Jensen, \& Zachariae, 2009).

Complementary health approach has become a popular form of healthcare and the predictions are that, it will increase further. The reasons for this level of popularity are highly diverse, and much of the motivation to turn to CHA pertains to a deeply felt criticism of mainstream medicine, many people (are led to) believe that conventional interventions, CHA optimizes supportive cancer care by offering non-pharmacologic approaches to symptoms of cancer and the heavy toxicities of its treatment, the practice of CHA is focused on improving the quality of life (QOL), optimal recovery, as well as promoting lifestyle changes that may reduce recurrence risks for some cancers (Sagar, 2008, Berretta et al., 2017).

Patients who use CHA do so most often at opposite ends of the disease spectrum either for chronic, minor illnesses (e.g. back pain or arthritis) or devastating, life-threatening conditions (e.g. cancer or AIDS). In both situations, conventional options may be perceived as either ineffective or too toxic. Besides perceived therapeutic benefits, many complementary therapies not only have few unpleasant adverse effects, but also actually induce pleasant side effects. Reflexology, aromatherapy and massage, for instance, can be very relaxing. The aims of CHA may be closer to those of patients than of conventional healthcare professionals. While physicians usually want to alter the course of pathological processes, patients simply want to feel better (Frass et al., 2012).

Cancer patients use CHA for disease-related symptoms, treatment-related adverse effects not addressed by conventional treatment, such as recurring pain, insomnia, and ongoing psychological distress, also they seek to improve quality of life, its presumed anti-neoplastic or cancer preventive properties, its presumed pro-immune activity, and more control and responsibility of their own care (Stub et al., 2016). However, the CHA use and practices among cancer patients in Egypt are limited. This study therefore to assess use, predictors and characteristics associated with use of complementary health approaches among patients with cancer.

\section{Significance of the Study}

Patients and caregivers, whose lives have been touched by cancer, deal with enormous stressors over the course of their diagnosis, treatment through survivorship, or end-of-life care. Despite the high prevalence of, research suggests that patients often do not discuss CHA use with their conventional health care provider. However, little is known about the use of CHA in patients with cancer specifically, also the use of CHA has increased steadily over the past 15 years or so, and definitely it has gained medical, economic and sociological importance (Stub et al., 2016).

Researchers observed through their clinical experience that large number of cancer patients utilize CHA without informing health care providers so a better examination of these topics is critical to develop better integration of CHA with conventional medical system and support patient-centered communication in cancer survivorship care in Egypt. Information on the use of CHA in patients with cancer is scarce. Given the disease and treatment complexities associated with the care of patients with cancer, oncology health care providers would benefit from having an appreciation of the extent of usage of unconventional, adjunctive therapies among these patients. This study evaluated the use, demographic and clinical predictors of CHA among patient with cancer.

The present study will add additional information on prediction and frequency of CHA use and generate hypotheses. A comprehensive medical history is paramount for nurses in order to achieve quality care, but patients do not always inform healthcare professionals about CHA use which can lead to harmful double treatment or medication. The study also offers information for CHA providers on the medical backgrounds of their patients. They can utilize this information to ensure safe care and assess the need for biomedical care. 


\subsection{Aim of the study}

The aim of the current study was to assess use, predictors and characteristics associated with use of complementary

health approaches among patients with cancer.

\subsection{Research Questions}

1. What is the frequency of CHA use among patients with cancer?

2. What are the different CHA used among patients with cancer?

3. What are the characteristics of CHA users among patients with cancer?

4. What are the predictors for using CHA among patients with cancer?

\section{Methodology}

\subsection{Research design}

Descriptive exploratory research design was utilized to achieve the aim of the current study.

\subsection{Setting}

The study was conducted in the Oncology and Nuclear medicine department affiliated to one of the University Hospital, Cairo-Egypt, during the period from November 2017 till June 2018.

\subsection{Sample}

A convenient sample of 150 adult male and female cancer patients who fulfill the inclusion and exclusion criteria enrolled in the study with the following inclusion and exclusion criteria. Inclusion Criteria: adult male and female cancer patients over or equal 18 years old and those who willing to participate in the study. Exclusion criteria: end of life patients, altered level of consciousness.

\subsection{Tools}

To achieve the aim of the current study the following questionnaire was used;

The data collection instrument was a 21-item questionnaire was developed after an extensive literature review, covering patient demographic features and medical data (6items) as age, sex, educational level, diagnosis, duration of disease .Treatment -related variables (4items), as type of treatment from the start of the disease, type of treatment was taken during the study, Is the treatment effective and. variables related to characteristics and predictors of CHA use (11items) as motive for starting CHA, its cost, desired effect, side effect, information received and different types of CHA as herbal, message, yoga, prayer drawing .........etc. On the cover page of the questionnaire, CHA was clearly defined as follows: "any therapy not included in the mainstream biomedical framework of care for patients. CHA means remedies that are used without the approval of the relevant government authorities, such as the Ministry of Health, that approve new drugs. CHA includes natural products, herbs, green tea, other special foods, megavitamins, acupuncture, aromatherapy, massage, meditation, and so on. The questionnaire was submitted to a panel of five experts in the field of Medical Surgical Nursing as well as Oncology and Nuclear Medicine to evaluate its content validity. Modifications were carried out according to expert's judgments on clarity of sentences and appropriateness of the contents. Reliability was established using Cronbach's $\alpha$ which showed a satisfactory level .The Cronbach's alpha reliability has been reported as 0.84 .

\subsection{Ethical considerations}

An official permission was obtained from the selected outpatient clinics' administrators. At the initial interview, each potential participant was informed about the purpose, the procedure, and the benefits of the study, and a cover letter explaining the research project was also read to them. They were informed as well that participation in the study is completely voluntary and they have the right to withdraw from the study at any time without any penalty. Confidentiality and anonymity were assured too.

\subsection{Pilot Study}

A pilot study was conducted on 6 participants at the specified unit, and these participants were excluded from the main study sample. The objectives of the pilot study were to fill in the entire questionnaires and to clarify the questions (whether any question was unclear or ambiguous). Modifications were done for some mysterious statements, otherwise, almost all items were clearly understood and the responses were found appropriate. Modifications were done on the final forms of the tool. The result of the pilot study confirmed that the study is feasible.

\subsection{Procedure:}

Every patient interviewed individually information related to the study was explained as well as all the previously mentioned ethical considerations, after agreement to participate in the study they asked to sign the consent. Then the questionnaire filled by the researcher through a structured interview while the participants were waiting in the waiting area before or after they met their oncologists. 


\subsection{Statistical Data Analysis:}

The data was coded and tabulated using a personal computer. Statistical Package for Social Science (SPSS) version 20 was used. Descriptive statistics were calculated on the use of specific CHA therapies. General linear regression analyses were conducted to examine the relationships between the number of individual types of CHA used and particular patient background characteristics (ie, age, marital status, education, activity of daily living, and performance status), Multivariable logistic regression analysis and cross tabulation were used to examine the relationship between patient background characteristics and the use of CHA.

\section{Results}

3.1. Section: I: Description of the studied Sample demographic and the medical data.

Table (1): Frequency and Percentage Distribution of Demographic \& Medical Characteristics of the Study Sample $(\mathbf{n}=\mathbf{1 5 0})$

\begin{tabular}{|c|c|c|}
\hline Demographic & No. & $\%$ \\
\hline \multicolumn{3}{|l|}{ Age } \\
\hline $18-30$ & 35 & 23.3 \\
\hline $31-44$ & 56 & 37.3 \\
\hline $45-59$ & 53 & 35.3 \\
\hline 60 or more & 6 & 4.1 \\
\hline \multicolumn{3}{|l|}{ Sex } \\
\hline Male & 92 & 61.3 \\
\hline Female & 58 & 38.7 \\
\hline \multicolumn{3}{|l|}{ Education level } \\
\hline Cannot read \&write & 16 & 10.7 \\
\hline Primary & 36 & 24.0 \\
\hline Secondary & 26 & 17.3 \\
\hline University & 72 & 48.0 \\
\hline \multicolumn{3}{|l|}{ Diagnosis } \\
\hline Lung & 12 & 8.0 \\
\hline Brest & 28 & 18.7 \\
\hline Hepatobiliary & 5 & 3.3 \\
\hline Genitourinary & 14 & 9.3 \\
\hline Gastrointestinal & 54 & 36.0 \\
\hline Blood & 25 & 16.7 \\
\hline Others & 12 & 8.0 \\
\hline \multicolumn{3}{|l|}{ Duration of disease } \\
\hline less than one year & 18 & 12.0 \\
\hline one to three years & 31 & 20.7 \\
\hline from three to five years & 47 & 31.3 \\
\hline more than 5years & 54 & 36.0 \\
\hline \multicolumn{3}{|l|}{ Activity of daily living } \\
\hline not specified & 41 & 27.3 \\
\hline limited & 50 & 33.3 \\
\hline bed rest more than $50 \%$ & 27 & 18.1 \\
\hline bed rest all the day & 32 & 21.3 \\
\hline
\end{tabular}

Table (1) depicted that more than one third of the study sample (37.3\%) their age ranges from 31-44, around two thirds $(61.3 \%)$ of the study sample were males. Nearly half of them $(48.0 \%)$ were graduated from university. Gastrointestinal cancer was the most prevalent cancer among study participants $(36.0 \%)$. Regarding duration of disease about (36.0\%) having cancer more than five years, about (33.3\%) had limited activity of daily living.

Section II: describing the use, predictors of complementary health approaches and characteristics of users among patients with cancer. 
Table (2): Frequency Distribution of the Study Sample Regarding Treatment Used (n=150)

\begin{tabular}{|l|c|c|}
\hline \multicolumn{1}{|c|}{ Item } & No. & \% \\
\hline Type of treatment from the start of the disease & 21 & 14.0 \\
Surgery & 70 & 46.7 \\
chemotherapy & 18 & 12.0 \\
hormonal & 27 & 18.0 \\
radiotherapy & 8 & 5.3 \\
palliative & 6 & 4.0 \\
others & & 6.7 \\
\hline Type of treatment you take now & 10 & 55.3 \\
surgery & 83 & 6.7 \\
chemo & 10 & 24.7 \\
hormonal & 37 & 6.0 \\
radio & 9 & .6 \\
palliative & 1 & 52.0 \\
others & & 48.0 \\
\hline Is the treatment effective & 78 & 54.0 \\
Yes & 72 & 46.0 \\
\hline No & & \\
\hline Change in outlook in life & 81 & \\
Yes & 69 & \\
no & & \\
\hline
\end{tabular}

Table (2) indicated that (46.7\%) received chemotherapy from the start of the disease, while half of the study sample $(55.3 \%)$ receiving chemotherapy at the time. Almost half of them $(52.0 \%)$ mentioned that the treatment were effective; and more than half $(54.0 \%)$ had change in outlook in life.

Table(3):Frequency Distribution of the Study Sample Regarding Characteristics of CHA Use (n=101)

\begin{tabular}{|c|c|c|}
\hline Item & No. & $\%$ \\
\hline $\begin{array}{l}\text { Use of CHA } \\
\text { yes } \\
\text { no }\end{array}$ & $\begin{array}{c}101 \\
49\end{array}$ & $\begin{array}{l}67.3 \\
32.7\end{array}$ \\
\hline $\begin{array}{l}\text { when you start to use it } \\
\text { months } \\
\text { years }\end{array}$ & $\begin{array}{l}40 \\
61 \\
\end{array}$ & $\begin{array}{l}27.3 \\
40.0 \\
\end{array}$ \\
\hline $\begin{array}{l}\text { Motive for starting CHA } \\
\text { advice from friends and family } \\
\text { my desire } \\
\text { the oncologist }\end{array}$ & $\begin{array}{c}39 \\
55 \\
7\end{array}$ & $\begin{array}{c}38.6 \\
54.5 \\
6.9\end{array}$ \\
\hline $\begin{array}{l}\text { do you tell your Dr. about using CHA } \\
\text { yes } \\
\text { no }\end{array}$ & $\begin{array}{l}19 \\
82\end{array}$ & $\begin{array}{l}18.8 \\
81.2\end{array}$ \\
\hline $\begin{array}{l}\text { Do you receive information about its effectiveness } \\
\text { yes } \\
\text { no }\end{array}$ & $\begin{array}{l}25 \\
76\end{array}$ & $\begin{array}{l}24.8 \\
75.2\end{array}$ \\
\hline $\begin{array}{l}\text { Is disease costly } \\
\text { yes } \\
\text { no }\end{array}$ & $\begin{array}{l}57 \\
42\end{array}$ & $\begin{array}{l}57.6 \\
42.4\end{array}$ \\
\hline $\begin{array}{l}\text { Does it promote its desired effect } \\
\text { yes } \\
\text { no } \\
\text { I don't know }\end{array}$ & $\begin{array}{l}70 \\
15 \\
16\end{array}$ & $\begin{array}{l}69.3 \\
14.9 \\
15.8\end{array}$ \\
\hline $\begin{array}{l}\text { Side effects } \\
\text { yes } \\
\text { no }\end{array}$ & $\begin{array}{l}17 \\
84\end{array}$ & $\begin{array}{l}16.8 \\
83.2\end{array}$ \\
\hline $\begin{array}{l}\text { Dr. response } \\
\text { encourage me to continue } \\
\text { ask me to stop } \\
\text { no response }\end{array}$ & $\begin{array}{l}58 \\
32 \\
11\end{array}$ & $\begin{array}{l}57.4 \\
31.7 \\
10.9\end{array}$ \\
\hline $\begin{array}{l}\text { Consulted with doctors about CHA use } \\
\text { Yes } \\
\text { no }\end{array}$ & $\begin{array}{l}19 \\
82 \\
\end{array}$ & $\begin{array}{l}18.8 \\
81.2\end{array}$ \\
\hline
\end{tabular}

Table (3) enlightens that more than two thirds (67.3\%) of the study sample were using CHA, about (40.0\%) of 
them using CHA for years. As regard the motives for using CHA more than half of the study sample (54.5\%) is using it because this is their desire. Also most of them (81.2\%) didn't tell their oncologists about using CHA, $(75.2 \%)$ didn't receive any information about using CHA. More than half $(57.6 \%)$ of the study sample considered the disease costly, in addition (69.3\%) agreed that it promotes its desired effect, $(83.2 \%)$ mentioned that it had no side effect. As regard doctor response of using CHA almost (57.4\%) stated that the oncologists encourage them to continue moreover, $(81.2 \%)$ doesn't consult the oncologist about using CHA.

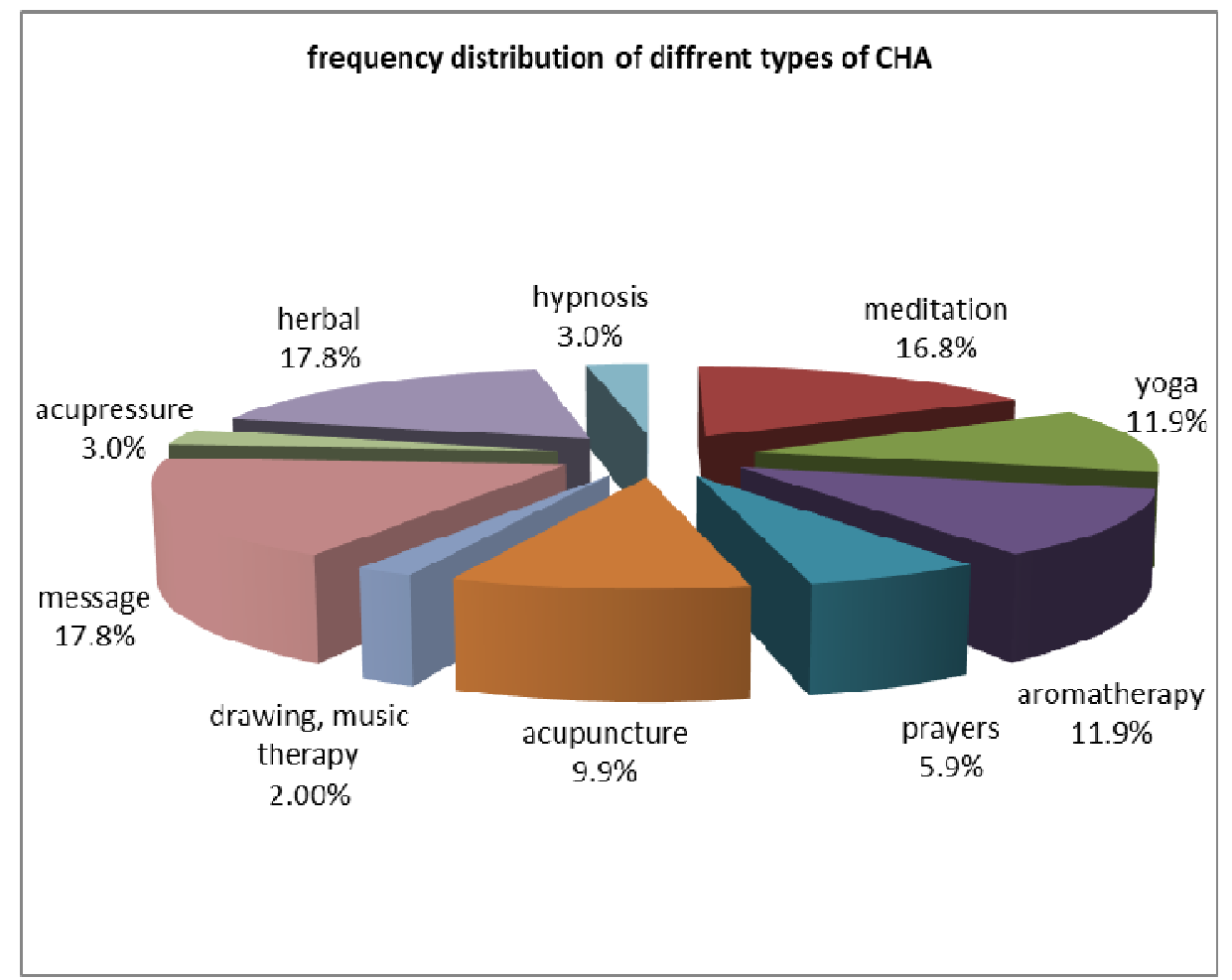

Figure (1): Frequency Distribution of the Study Sample as Regard Types of Used CHA (n=101)

It is apparent from Figure (1) that the most frequent types of CHA used by the study sample were massage, herbal products and meditation (17.8\% $17.8 \%$ and $16.8 \%)$ respectively.

Table(4): CrossTabulation of Study Sample Using CHA: Characteristics of CHA Users (n=101) and NonCHA Users (n=49)

\begin{tabular}{|c|c|c|c|c|c|c|}
\hline \multirow{2}{*}{\multicolumn{2}{|c|}{ items }} & \multicolumn{2}{|c|}{ do you use CHA } & \multirow{2}{*}{ Total } & Chi & P-value \\
\hline & & yes & No & & \multirow{5}{*}{15.741} & \multirow{5}{*}{0.001} \\
\hline \multirow{4}{*}{ Age } & $18-30$ & 30 & 5 & 35 & & \\
\hline & $31-44$ & 42 & 14 & 56 & & \\
\hline & $45-59$ & 26 & 27 & 53 & & \\
\hline & 60 and more & 3 & 3 & 6 & & \\
\hline \multirow{2}{*}{$\begin{array}{l}\text { Duration of } \\
\text { disease }\end{array}$} & Less than one year & 0 & 3 & 3 & \multirow[t]{2}{*}{6.310} & \multirow[t]{2}{*}{.012} \\
\hline & More than one year & 101 & 46 & 147 & & \\
\hline \multirow{7}{*}{ diagnosis } & lung & 7 & 5 & 12 & \multirow{7}{*}{15.787} & \multirow{7}{*}{0.015} \\
\hline & breast & 19 & 9 & 28 & & \\
\hline & hepatobilliary & 5 & 0 & 5 & & \\
\hline & genitourinary & 11 & 3 & 14 & & \\
\hline & gastrointestinal & 33 & 21 & 54 & & \\
\hline & blood & 22 & 3 & 25 & & \\
\hline & others & 4 & 8 & 12 & & \\
\hline \multirow{4}{*}{$\begin{array}{l}\text { activity of } \\
\text { daily living }\end{array}$} & not specified & 23 & 18 & 41 & \multirow{4}{*}{8.066} & \multirow{4}{*}{0.045} \\
\hline & limited with little symptom & 39 & 11 & 50 & & \\
\hline & bed rest more than $50 \%$ & 21 & 6 & 27 & & \\
\hline & bed rest all the day & 18 & 14 & 32 & & \\
\hline \multirow{4}{*}{$\begin{array}{l}\text { date of } \\
\text { disease }\end{array}$} & less than one year & 8 & 10 & 18 & \multirow{4}{*}{5.497} & \multirow{4}{*}{0.139} \\
\hline & one to three years & 23 & 8 & 31 & & \\
\hline & from three to five years & 34 & 13 & 47 & & \\
\hline & more than 5years & 36 & 18 & 54 & & \\
\hline
\end{tabular}

$\underline{* P-v a l u e ~} \leq \mathbf{0 . 0 5}$ 
Table (4) explains that there is a significant relationships between age, diagnosis and activity of daily living and the use of CHA, in which younger age using CHA more frequently than older, on the other hand patient with genitourinary and blood cancer were using CAM more than others, While, patient with limited and decreased activity of daily living were the most users of CHA.

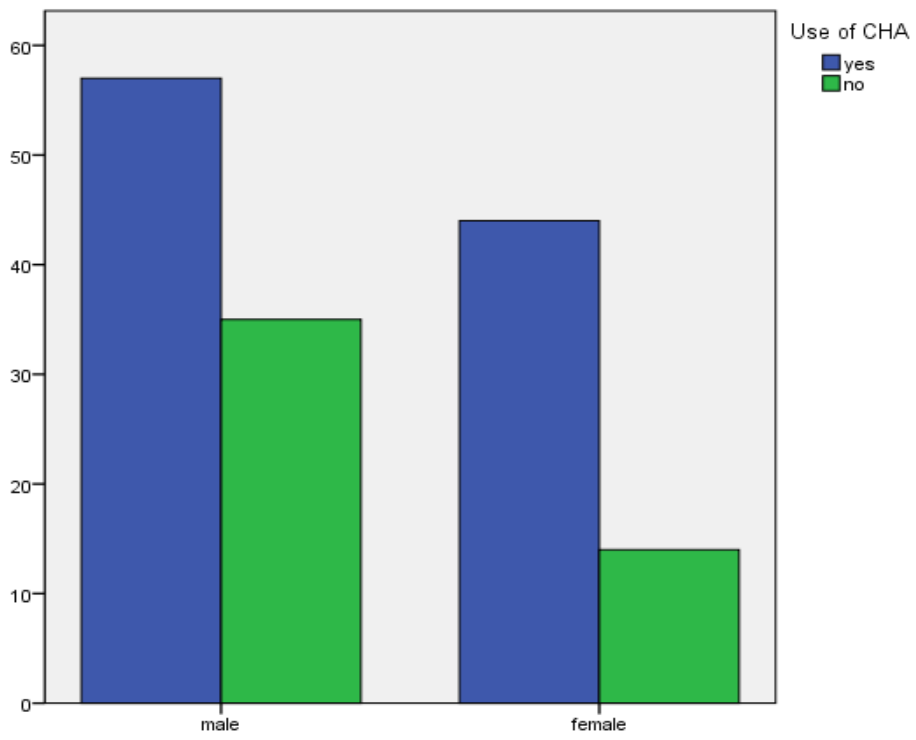

Figure (2): Comparison of the CHA Users and Nonusers in Relation to Gender $(n=150)$. As can be seen from figure (2) CHA use is greater among male than female cancer patients.

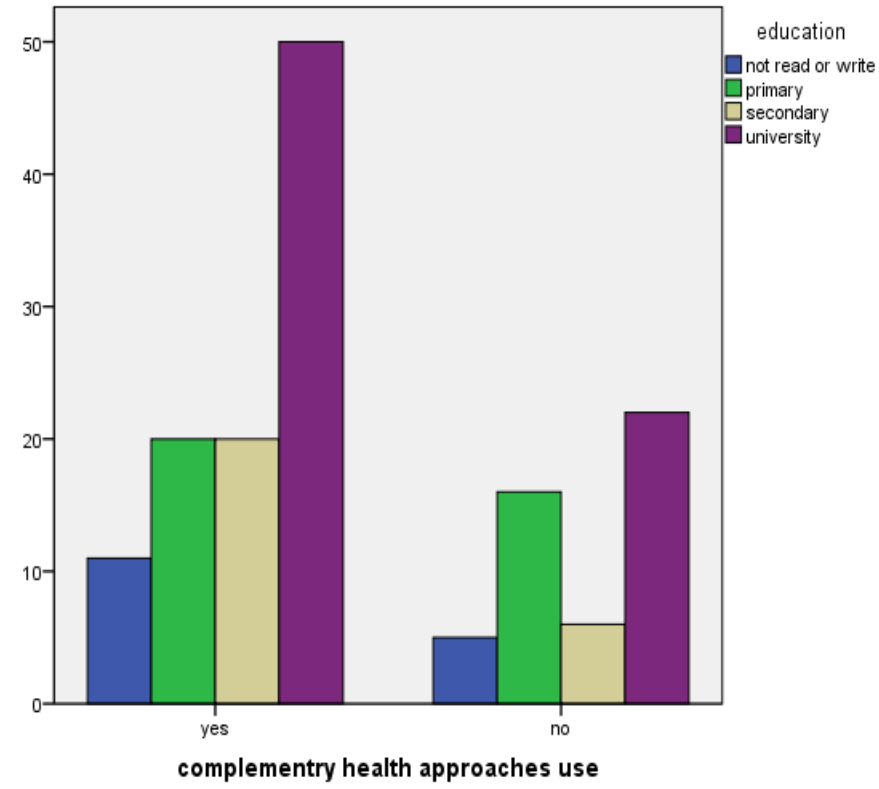

Figure (3): Comparison of the CHA Users and Nonusers in Relation to Education (n=150). Figure (3) portrays that CHA use is greater among highly educated people. 
Table (4): Predictors of CHA Use Using Multivariate logistic Regression Analysis:

\begin{tabular}{|c|c|c|c|c|}
\hline \multirow[t]{2}{*}{ Variables } & \multirow[t]{2}{*}{$P$ value } & \multirow[t]{2}{*}{$\begin{array}{l}\text { Odds } \\
\text { Ratio }\end{array}$} & \multicolumn{2}{|c|}{$\begin{array}{l}95 \% \text { CI for Odds } \\
\text { Ratio }\end{array}$} \\
\hline & & & Lower & Upper \\
\hline age & $.010 *$ & 4.970 & 1.465 & 16.866 \\
\hline sex & .241 & .600 & .255 & 1.410 \\
\hline education & .242 & 2.224 & .582 & 8.497 \\
\hline duration of disease & .999 & .000 & .000 & .000 \\
\hline date of disease & .061 & .311 & .091 & 1.058 \\
\hline diagnosis & .354 & .504 & .118 & 2.149 \\
\hline activity of daily living & $.033 *$ & .346 & .130 & .916 \\
\hline type of treatment from the start of the disease & .418 & .621 & .196 & 1.969 \\
\hline type of treatment you take now & .133 & .311 & .068 & 1.428 \\
\hline treatment effective & .089 & 2.158 & .889 & 5.236 \\
\hline change in outlook in life & .076 & 2.106 & .925 & 4.796 \\
\hline
\end{tabular}

\section{*P-value $\leq \mathbf{0 . 0 5}$}

Table (4) discloses that the significant predictors of CHA use using multivariate logistic regression analysis were found to be age ( $\mathrm{p}$ value $=0.010)$, and activity of daily living ( $\mathrm{p}$ value $=0.033)$. Young age $(18-30)$ increases $\mathrm{CHA}$ use by 4.9 times than older ages. Limited and decreased activity of daily living increases CHA use by .346 times.

\section{Discussion}

The use of CHA in cancer patients with conventional treatments such as chemotherapy, radiation and surgery is growing over the past 15 years, not only in Western countries, but also in the Far East or in developing countries. So it has undoubtedly gained medical, economic and research importance (Rossi et al., 2015, Kessel et al., 2016). Nevertheless the literature about CHA prevalence in cancer patients is not particularly rich. Many patients do not declare that they engage in this practice, on one hand because they undervalue the potential interaction of these therapies with the conventional drugs, and, on the other hand, because they are somehow reluctant to admit the use of CHA, worrying that such behavior may be interpreted as reflecting a loss of trust in oncologist and the treatment has prescribed (Berretta et al., 2017).

The study on hand shed the light on that more than two thirds of the study sample were using CHA in combination with the conventional treatment of cancer. This figure is approximately near to previously reported figures from other countries like Korea (78.5\%), Scotland (55\%) and Switzerland (53\%) (Rossi et al., 2015). In a survey done by King et al.,(2015) approximately $47 \%$ of cancer patients have reported the use of various CHA. The largest survey in Europe on the use of CHA in cancer patients showed that, more than one third of cancer patients reported using some form of CHA, with little variation across countries (Rossi et al., 2015). An Egyptian study showed that $23 \%$ of the studied cancer patients received CHA. Scarcity of previous studies conducted in Egypt on prevalence of CHA hinders comparing and tracing the trend of CHA use (Abdelmoaty et al., 2018). The noted difference of CHA utilization rate between several studies could be most likely due to multiple factors such as the lack of standardized definitions and methods utilized to assess CHA usage, differences in culture, socioeconomic condition, and/or study methodology itself.

The most frequent CHA used by the current study sample were herbs, massage and meditation, where nearly one fifth of them used these modalities. This is in line with Fremd et al. (2017) who stressed that across many countries, herbals, homeopathy, relaxation techniques like massage, prayer as well as food supplements and vitamins are most popular CHA used strategies among German patients with breast cancer. El Nimr, Wahdan, Wahdan, \& Kotb (2015)) investigated the prevalence of complementary and alternative medicines in Alexandria, Egypt reported that the most frequently used CHA in general population not specifically in cancer were herbs $(91.6 \%)$, followed by spiritual healing $(9.4 \%)$ and cupping and acupuncture $(6.4 \%)$.

According to the study by Rossi et al., exploring the use of CHA in Italian cancer patients in six cancer departments, $37.9 \%$ of patients use one or more types of CHA: diet and food supplements $(27.5 \%)$, herbal medicine $(10.8 \%)$, homeopathy $(6.4 \%)$ and body-mind therapies $(5.5 \%)$; a high percentage of patients $(66.3 \%)$ also inform the physicians of this choice and the benefits they experience (89.6\%)(Rossi, Di Stefano, Firenzuoli, Monechi, \& Baccetti, 2017). The most popular modalities of CHA used for cancer-related outcomes were herbal medicine $(32.9 \%)$, mind-body therapies $(29.4 \%)$ as reported in a study examined the complementary and alternative medicine use among patients with cancer in Mongolia (Oyunchimeg, Hwang, Ahmed, Choi, \& Han, 2017). Alongside the traditional use of herbs, it is possible today to use herbal medicine in trials based on 
documented clinical evidence, generally to relieve the most common symptoms, when these prove to be drug resistant (Rossi et al., 2017).

Regarding characteristics of the study sample using CHA, the findings of the present study exhibited that more than one third of them using CHA for years. As regard the motives for using CHA, more than half of the study sample was using CHA according to their own preferences. Also the vast majority of them neither consult nor telling their oncologists about using CHA and stated that it promotes its desired effect with more than two thirds of them reported no side effects. The majority of the study sample didn't receive any information regarding CHA from health care providers. As regard doctor response of using CHA more than half of the study sample stated that the oncologists encourage them to continue.

The majority of users believed that CHA was effective. However, it is difficult to say whether these improvements were related to use of CHA, since all patients received conventional cancer treatment at the same time. Similar to past studies, a relatively small proportion of CHA users made their doctors aware of their decision to use CHA. This could be dangerous, specifically in the area of oncology, where treatment methods and procedures are becoming more and more advanced. The risk of interaction between patients' use of CHA by their own decision and conventional treatment might jeopardize their life, as evidence suggests that consumption of complementary therapy can have negative effects when used concurrently with conventional radiotherapy and/or chemotherapy. Therefore, it is recommended that clinicians and nurses should be more aware of patients' health care behavior (Oyunchimeg et al., 2017).

On the contrary to our results Suzuki et al. (2017) found that the main motive for CHA use was the recommendation of family members or friends. The population of patients who were willing to seek out CHA on their own was unexpectedly small, about one fourth of the users. In congruent with the current study findings the latter authors reported that most cancer patients use CHA without any harmful influence on their cancer treatment; however, in some patients, CHA incurs a large expense and a delay in starting cancer treatment.

Cross tabulation of the current study sample to examine the characteristics of CHA users and non-CHA users revealed that there are significant relationships between age, sex, education, diagnosis and activity of daily living and the use of CHA, in which younger age using CHA more frequently than older, CHA use is greater among male than females. CHA use is greater among highly educated patients. On the other hand people with genitourinary and blood cancer were using CHA more than others. Patients with limited and decreased activity of daily living were the most users of CHA.

In view of the existing study findings and in line with findings of previous studies where younger age, higher level of education were associated with CHA use (Oyunchimeg et al., 2017). Another study proposed that CHA users differed from non CHA users based on their age (more likely to be younger or middle aged), gender (female), level of education (college degree or higher) (Kemppainen, Kemppainen, Reippainen, Salmenniemi, \& Vuolanto, 2018), cancer diagnosis (breast or ovarian) (Sohl et al., 2014).The researchers justify the use of CHA by educated patients by that probably a high education level allows easier access to the media, internet and information about medicine.

In accord to our results the authors reported that males were discerning in their evaluation of CHA information, offered rationales for their choices and often adopted a 'consumerist' approach to CHA treatment options(Evans et al., 2007). Most studies have shown that either younger patients $<40$ years of age or retirees significantly more often use CHA. Females are significantly more often open to CHA than males, opposing our results. However, some studies have not confirmed this higher prevalence in women or in patients with higher education (Kessel et al., 2016). The European survey published by Molassiotis et al. included 956 patients from fourteen countries described that despite suggestions from the literature that breast cancer patients are more likely to use CHA compared with other cancer patients, the study showed that pancreatic, liver, bone and brain cancer patients used CHA therapies significantly more often than any other cancer patient group (Molassiotis et al., 2005).

Predictors of higher CHA use by patients with cancer in the current study were age and the activity of daily living, where younger participants and those with decreased activity of daily living were more likely to use CHA.

The researchers could explains these findings in the light of the fact that younger participants and those who are with decreased activity of daily living sought a mean rather than conventional treatment, one aspect is the common belief that different methods of CHA have the potential to boost the immune system and to strengthen 
the body to fight cancer. Therefore it will help them to improve their general wellbeing.

In a study done by Anderson \& Taylor found that predictors of higher CHA use by patients with cancer were female gender, stage of disease at diagnosis, age, higher education, higher income, race, and geographical location (Anderson \& Taylor, 2012). Regarding our study results revealed that age, gender, level of education, diagnosis were not predictors to CHA use but considered only significant characteristics of CHA users. Similar to our result (Bahall, 2017) clarified that CHA use was associated with age, but no predictors of CHA use could be identified.

In contrary to our study findings (El Nimr et al., 2015)revealed that age, occupation and the presence of chronic conditions were the independent factors significantly predicting the practice of self-medication and CHA usage. Moreover Suzuki et al.(2017)showed that CHA use is significantly associated with younger patients and highly educated families. This holds true in multivariate analysis done by (Fremd et al., 2017)and confirmed the patient's age as predictive for interest in CHA. Berretta et al.(2017) study demonstrated that a higher functional status (less impairment with activities of daily living, was predictive of CHA use with no difference was noticed between males and females.

Altogether, Use of unconventional therapies is pervasive among cancer patients, particularly among those who are younger and highly educated. Oncology providers need to assess patients' complementary therapy use and consider potential interactions with prescribed treatment protocols.

\section{Conclusion}

Complementary health approach appears to be widely accepted by patients with cancer in the study sample. Health care providers especially oncology nurse should take the initiative to ask whether patients are using any CHA, so they can provide evidence-based consultation concerning the appropriateness of using CHA during conventional cancer treatment. The findings support the urgent need. High CHA use among patients with cancer in our study warrants further studies in other countries of this region.

\section{Recommendations of the Study}

Based on the study results, the following recommendations were suggested:

1. Further in-depth study into commonly used CHA products and their potential effects on health of cancer population in Egypt.

2. Replication of this study among a larger sample from various settings is requested to generalize the results.

\section{Acknowledgement}

The researchers are extremely grateful to all participants of this research.

\section{References}

Abdelmoaty, A. M., Amin, T. T., Obaid, H. A., Abdelsadek, O. A. A., Hassan, U. H. B., Abdelazeim, N. A., \& Janoudi, S. L. (2018). Complementary Medicines among Egyptian Oncology Patients at a Tertiary Level of Care: Pattern and Motives. Health Science Journal, 12(2). https://doi.org/10.21767/1791-809X.1000561

Anderson, J. G., \& Taylor, A. G. (2012). Use of complementary therapies for cancer symptom management: results of the 2007 National Health Interview Survey. The Journal of Alternative and Complementary Medicine, 18(3), 235-241.

Bahall, M. (2017). Prevalence, patterns, and perceived value of complementary and alternative medicine among cancer patients: a cross-sectional, descriptive study. BMC Complementary and Alternative Medicine, 17(1), 345. https://doi.org/10.1186/s12906-017-1853-6

Berretta, M., Pepa, C. D., Tralongo, P., Fulvi, A., Martellotta, F., Lleshi, A., ... Facchini, G. (2017). Use of Complementary and Alternative Medicine (CAM) in cancer patients: An Italian multicenter survey. Oncotarget, 8(15), 24401-24414. https://doi.org/10.18632/oncotarget.14224

Bishop, F. L., \& Lewith, G. T. (2010). Who uses CAM? A narrative review of demographic characteristics and health factors associated with CAM use. Evidence-Based Complementary and Alternative Medicine, 7(1), 11-28.

Deng, G. E., \& Latte-Naor, S. (2018). Integrative Oncology: The Role of Complementary Medicine in Supportive Cancer Care. In The MASCC Textbook of Cancer Supportive Care and Survivorship (pp. 145-161). Springer.

El Nimr, N. A., Wahdan, I. M. H., Wahdan, A. M. H., \& Kotb, R. E. (2015). Self-medication with drugs and complementary and alternative medicines in Alexandria, Egypt:prevalence, patterns and determinants. EMHJ-Eastern Mediterranean Health Journal, 21(4), 256-265. Retrieved from http://apps.who.int/iris/handle/10665/255095

Evans, M., Shaw, A., Thompson, E. A., Falk, S., Turton, P., Thompson, T., \& Sharp, D. (2007). Decisions to use complementary and alternative medicine (CAM) by male cancer patients: information-seeking roles and types of evidence used. BMC Complementary and Alternative Medicine, 7(1), 25. 
Frass, M., Strassl, R. P., Friehs, H., Müllner, M., Kundi, M., \& Kaye, A. D. (2012). Use and acceptance of complementary and alternative medicine among the general population and medical personnel: a systematic review. The Ochsner Journal, 12(1), 45-56.

Fremd, C., Hack, C. C., Schneeweiss, A., Rauch, G., Wallwiener, D., Brucker, S. Y., ... Wallwiener, M. (2017). Use of complementary and integrative medicine among German breast cancer patients: predictors and implications for patient care within the PRAEGNANT study network. Archives of Gynecology and Obstetrics, 295(5), 1239-1245. https://doi.org/10.1007/s00404-017-4348-2

Hall, H., Brosnan, C., Frawley, J., Wardle, J., Collins, M., \& Leach, M. (2018). Nurses' communication regarding patients' use of complementary and alternative medicine. Collegian, 25(3), 285-291.

Kemppainen, L. M., Kemppainen, T. T., Reippainen, J. A., Salmenniemi, S. T., \& Vuolanto, P. H. (2018). Use of complementary and alternative medicine in Europe: Health-related and sociodemographic determinants. Scandinavian Journal of Public Health, 46(4), 448-455. https://doi.org/10.1177/1403494817733869

Kessel, K. A., Lettner, S., Kessel, C., Bier, H., Biedermann, T., Friess, H., .. Combs, S. E. (2016). Use of Complementary and Alternative Medicine (CAM) as Part of the Oncological Treatment: Survey about Patients' Attitude towards CAM in a University-Based Oncology Center in Germany. PLOS ONE, 11(11), e0165801. https://doi.org/10.1371/journal.pone.0165801

King, N., Balneaves, L. G., Levin, G. T., Nguyen, T., Nation, J. G., Card, C., ... Carlson, L. E. (2015). Surveys of Cancer Patients and Cancer Health Care Providers Regarding Complementary Therapy Use, Communication, and Information Needs. Integrative Cancer Therapies, 14(6), 515-524. https://doi.org/10.1177/1534735415589984

Letourneau, M. D. (2018). Social Learning Biases in the Use of Complementary and Alternative Medicine.

Molassiotis, A., Fernandez-Ortega, P., Pud, D., Ozden, G., Scott, J. A., Panteli, V., ... Selvekerova, S. (2005). Use of complementary and alternative medicine in cancer patients: a European survey. Annals of Oncology, 16(4), 655-663.

Oyunchimeg, B., Hwang, J. H., Ahmed, M., Choi, S., \& Han, D. (2017). Complementary and alternative medicine use among patients with cancer in Mongolia: a National hospital survey. BMC Complementary and Alternative Medicine, 17(1), 58. https://doi.org/10.1186/s12906-017-1576-8

Pedersen, C. G., Christensen, S., Jensen, A. B., \& Zachariae, R. (2009). Prevalence, socio-demographic and clinical predictors of post-diagnostic utilisation of different types of complementary and alternative medicine (CAM) in a nationwide cohort of Danish women treated for primary breast cancer. European Journal of Cancer, 45(18), 31723181.

Rossi, E., Di Stefano, M., Firenzuoli, F., Monechi, M. V., \& Baccetti, S. (2017). Add-On Complementary Medicine in Cancer Care: Evidence in Literature and Experiences of Integration. Medicines, 4(1), 5. https://doi.org/10.3390/medicines4010005

Rossi, E., Vita, A., Baccetti, S., Di Stefano, M., Voller, F., \& Zanobini, A. (2015). Complementary and alternative medicine for cancer patients: results of the EPAAC survey on integrative oncology centres in Europe. Supportive Care in Cancer, 23(6), 1795-1806. https://doi.org/10.1007/s00520-014-2517-4

Sagar, S. M. (2008). How do we evaluate outcome in an integrative oncology program? Current Oncology, 15(Suppl 2), s78.

Sohl, S. J., Weaver, K. E., Birdee, G., Kent, E. E., Danhauer, S. C., \& Hamilton, A. S. (2014). Characteristics associated with the use of complementary health approaches among long-term cancer survivors. Supportive Care in Cancer, 22(4), $927-936$

Stub, T., Quandt, S. A., Arcury, T. A., Sandberg, J. C., Kristoffersen, A. E., Musial, F., \& Salamonsen, A. (2016). Perception of risk and communication among conventional and complementary health care providers involving cancer patients' use of complementary therapies: a literature review. BMC Complementary and Alternative Medicine, $16(1), 353$.

Suzuki, K., Morita, T., Tanaka, K., Tei, Y., Azuma, Y., Igarashi, N., ... Miyashita, M. (2017). Nationwide Survey on Complementary and Alternative Medicine (CAM) in Cancer Patients Who Died at Palliative Care Units in Japan: Prevalence of CAM and Family Experience. Palliative Care Research, 12(4), 731-737. Retrieved from http://wprim.whocc.org.cn/admin/article/articleDetail?WPRIMID=379447\&articleId=379447\&locale=en_US 